\title{
Heterogeneous OH oxidation of palmitic acid in single component and internally mixed aerosol particles: vaporization and the role of particle phase
}

\author{
V. F. McNeill ${ }^{1,2}$, R. L. N. Yatavelli ${ }^{1}$, J. A. Thornton ${ }^{1}$, C. B. Stipe ${ }^{3}$, and O. Landgrebe ${ }^{1}$ \\ ${ }^{1}$ Department of Atmospheric Sciences, University of Washington, Seattle, Washington, 98195, USA \\ ${ }^{2}$ Department of Chemical Engineering, Columbia University, New York, New York, 10027, USA \\ ${ }^{3}$ Department of Mechanical Engineering, Seattle University, Seattle, Washington, 98122, USA
}

Received: 13 February 2008 - Published in Atmos. Chem. Phys. Discuss.: 26 March 2008

Revised: 7 July 2008 - Accepted: 19 August 2008 - Published: 12 September 2008

\begin{abstract}
We studied the $\mathrm{OH}$ oxidation of submicron aerosol particles consisting of pure palmitic acid (PA) or thin (near monolayer) coatings of PA on aqueous and effloresced inorganic salt particles. Experiments were performed as a function of particle size and $\mathrm{OH}$ exposure using a continuousflow photochemical reaction chamber coupled to a chemical ionization mass spectrometer (CIMS) system, for detection of gas and particle-bound organics, and a DMA/CPC for monitoring particle size distributions. The loss rate of PA observed for pure PA aerosols and PA on crystalline $\mathrm{NaCl}$ aerosols indicates that the $\mathrm{OH}$ oxidation of $\mathrm{PA}$ at the gas-aerosol interface is efficient. The pure PA oxidation data are well represented by a model consisting of four main processes: 1) surface-only reactions between $\mathrm{OH}$ and palmitic acid, 2) secondary reactions between palmitic acid and $\mathrm{OH}$ oxidation products, 3) volatilization of condensedphase mass, and 4) a surface renewal process. Using this model we infer a value of $\gamma^{\mathrm{OH}}$ between 0.8 and 1 . The oxidation of palmitic acid in thin film coatings of salt particles is also efficient, though the inferred $\gamma^{\mathrm{OH}}$ is lower, ranging from $\sim 0.3(+0.1 /-0.05)$ for coatings on solid $\mathrm{NaCl}$ and $\sim 0.05$ ( \pm 0.01$)$ on aqueous $\mathrm{NaCl}$ particles. These results, together with simultaneous data on particle size change and volatilized oxidation products, provide support for the ideas that oxidative aging of aliphatic organic aerosol is a source of small oxidized volatile organic compounds (OVOCs), and that $\mathrm{OH}$ oxidation may initiate secondary condensed-phase reactions.
\end{abstract}

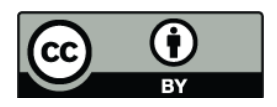

Correspondence to: J. A. Thornton (thornton@atmos.washington.edu)

\section{Introduction}

Atmospheric aerosols impact Earth's radiation balance both directly by scattering solar radiation and indirectly via cloud properties (Forster et al., 2007), and they influence atmospheric composition via heterogeneous and multiphase chemistry (Jacob, 2000; Liao and Seinfeld, 2005). Organic matter typically comprises 10 to $90 \%$ of tropospheric fine aerosol mass (Kanakidou et al., 2005). Recently, this prevalence and importance has renewed interest in the sources and sinks of aerosol organic matter, with heterogeneous aging by atmospheric oxidants gaining significant attention (Rudich et al., 2007). One motivation has been to characterize the timescale and mechanisms for converting the aerosol material from hydrophobic to hydrophilic via oxidation. Such a conversion may alter both the radiative properties of the aerosol, by increasing water uptake, and their cloud droplet nucleating ability. Heterogeneous oxidation also has the potential to induce volatilization of condensed-phase material via radical decomposition, which would lead to reduced particle mass and would serve as a source of oxidized volatile organic compounds (OVOCs) (Molina et al., 2004).

Particle phase and morphology have been observed to affect the aging process, and also to change with aging, mainly in the case of $\mathrm{O}_{3}$ oxidation (Knopf et al., 2005; Hearn and Smith, 2005; Katrib et al., 2005; Hearn and Smith, 2007). While $\mathrm{OH}$ oxidation has been much less studied in this regard, it has also been observed to induce changes in particle density (George et al., 2007). Heterogeneous oxidation could convert solid organic particles into more liquid-like particles by increasing the number of components and functionality (Marcolli et al., 2004). Gas-phase oxidants will undergo slow diffusion in a solid organic matrix or in viscous liquids such

Published by Copernicus Publications on behalf of the European Geosciences Union. 




Fig. 1. Schematic of the experimental set-up

as those that are supercooled or structured (Hearn and Smith, 2005; Katrib et al., 2005; Knopf et al., 2005). Therefore, the reactive zone for $\mathrm{OH}$ oxidation, which is expected to be fast (Bertram et al., 2001; Molina et al., 2004; Lambe et al., 2007; George et al., 2007), may be confined to the particle surface or near-surface region (Hanson et al., 1994; Worsnop et al., 2002) leading to differences in the transformation rates between the surface and bulk (Maria et al., 2004). To our knowledge, this aspect has not been thoroughly examined by laboratory studies.

Recent studies offer conflicting evidence as to the prevalence of secondary condensed-phase chemistry and also mass loss by volatilization initiated by heterogeneous oxidation. Molina et al. (2004) showed that OH oxidation of selfassembled monolayers (SAMs) led to the volatilization of about 6-9 carbons per OH collision. Hearn et al. (2007) used a relative rates technique to study $\mathrm{Cl}$-initiated oxidation of liquid bis(2-ethylhexyl) sebacate (BES) particles and found that the reaction probability, $\gamma^{C l} \sim 2$. They concluded that a reaction probability exceeding unity implied the existence of radical-assisted secondary chemistry occuring in the particle bulk. In contrast, George and coworkers used the aerosol flow tube technique to study the oxidation of liquid BES particles with $\mathrm{OH}$ in the absence of $\mathrm{NO}_{\mathrm{x}}$ (George et al., 2007). They observed very efficient oxidation $\left(\gamma^{\mathrm{OH}} 1.3 \pm 0.4\right)$ but no strong indication of secondary chemistry. From the observed particle size and density changes, and condensed phase product information, George et al. (2007) concluded that the predominant fate of the organic peroxy radical product $\left(\mathrm{RO}_{2}\right)$ was self reaction to form condensed-phase carbonyl and alcohol products. Alkoxy radical formation and subsequent volatilization due to decomposition was found to be a minor reaction pathway. The same group used PTR-MS to measure VOC yields from the $\mathrm{OH}$ oxidation of BES, soot, stearic acid, and pyrene films (Vlasenko et al., 2008). They observed a variety of volatile oxidation products, including formic acid. They found that VOC yield varied for the different film types, with stearic acid showing the most significant volatilization. Lambe et al. (2007) studied the $\mathrm{OH}$ oxidation of hexacosane, which is a solid at room temperature, in an aerosol chamber with AMS detection. They report efficient oxidation, with $\gamma^{\mathrm{OH}}=1.04 \pm 0.21$ and report volatilization and secondary chemistry to be minor.It is clear that substantial uncertainty remains as to the potential for heterogeneous oxidation to initiate secondary chemistry and volatilization, and how these processes might depend on particle morphologies or composition.

We present a laboratory investigation of the $\mathrm{OH}$ oxidation of pure palmitic acid aerosols and palmitic acid present as a thin (near monolayer) film on $\mathrm{NaCl}$ particles. One motivation of this study was to extend the investigations of $\mathrm{OH}$ oxidation to particles with different compositions, using the same experimental technique, for direct comparion of reactivity differences. By using palmitic acid in surface films and pure particles we tried to span the regimes examined in separate studies using SAMs or single component particles. The results from both sets of our experiments, while showing some differences, are consistent with efficient oxidation occurring at the particle surface, and provide evidence for secondary condensed-phase chemistry, especially in the pure particle case. Evidence also exists for volatilization of oxidation products in the observed particle size changes and low-molecular weight species detected by mass spectrometry upon $\mathrm{OH}$ exposure. The data are represented well by a model that assumes palmitic acid reacts with $\mathrm{OH}$ and oxidation products, these reactions occur only at the particle surface, a process exists (i.e. volatilization) to renew the particle surface with palmitic acid from the bulk, and particle mass loss due to volatilization occurs at a rate proportional to the palmitic acid loss rate.

\section{Experimental}

Experiments were performed using a continuous flow photochemical reaction chamber coupled to a chemical ionization mass spectrometer (CIMS) system. Volatilization and detection of organics in the particle phase was achieved using a heated inlet for thermal desorption. A differential mobility analyzer/condensation particle counter (DMA/CPC, Grimm Technologies) was used for measuring aerosol size distributions. The setup is similar to that described in McNeill, et al. (2007), but we provide a summary and important differences below. Figure 1 shows a schematic of the apparatus.

\subsection{Aerosol generation and characterization}

Pure palmitic acid aerosols were generated via homogeneous nucleation as described in Thornton et al. (2003). A $30 \mathrm{~cm}$ long, $13 \mathrm{~mm}$ O.D. Pyrex tube was loaded with pure palmitic acid crystals and wrapped in heating tape, and a thermocouple measured the external temperature of the tube. A temperature controller (Omega) was used to maintain the 
particle source at $95-115^{\circ} \mathrm{C}$. Particles were entrained in a flow of $500 \mathrm{sccm}$ dry $\mathrm{N}_{2}$. Mean particle size was controlled by changing the source temperature and/or the bulk flow rate. In some experiments, smaller sizes were achieved by passing the source effluent through a second empty heated tube which served to partially evaporate and denude excess palmitic acid. The resulting aerosol stream was mixed with $2 \mathrm{slpm} \mathrm{N} \mathrm{N}_{2}$ carrier gas. The carrier gas was humidified to approximately $16 \% \mathrm{RH}$ for $\mathrm{OH}$ generation (see below). In some experiments, an additional stream of $500 \mathrm{sccm} \mathrm{O}_{2}$ was also added and the $\mathrm{N}_{2}$ carrier flow was reduced, to simulate a $20 \% \mathrm{O}_{2}$ atmosphere in the reactor.

Palmitic acid-coated $\mathrm{NaCl}$ particles were made via vapor deposition of palmitic acid onto crystallized salt particles following Kwamena et al. (2004). $\mathrm{NaCl}$ particles were generated by a constant output atomizer (TSI) operating with a $0.05 \mathrm{M}$ solution of $\mathrm{NaCl}$ in deionized water. A $1 \mathrm{slpm}$ portion of the atomizer output passed through a diffusion drier before entering the palmitic acid source to insure the submicron $\mathrm{NaCl}$ particles were effloresced. For coating, the temperature of the palmitic acid source (described above) was maintained at $70-80^{\circ} \mathrm{C}$. At the exit of the palmitic acid source, the coated particles were mixed with $\sim 1.5 \mathrm{slpm} \mathrm{N}_{2}$ carrier flow. For the experiments performed on solid salt particles, the carrier gas was humidified to approximately $16 \% \mathrm{RH}$ for $\mathrm{OH}$ generation, but the aerosol stream was not further humidified before entering the photochemical reaction chamber. $\mathrm{NaCl}$ aerosol crystallize at $43 \% \mathrm{RH}$ and deliquesce at $\mathrm{RH} \sim 75 \%$ (Cziczo et al., 1997; Tang et al., 1997), thus we assume the aerosol remained crystalline during $\mathrm{OH}$ exposure under these conditions. For the experiments involving aqueous aerosols, the aerosol stream was passed through an in-line humidifier to raise the $\mathrm{RH}$ above the deliquescence point $(\mathrm{RH} \geq 80 \%$ for $\mathrm{NaCl}$ ) before entering the reactor. The humidifier was $20 \mathrm{~cm}$ long and consisted of $6 \mathrm{~mm}$ OD permeable Teflon tubing (Zeus, Inc.) housed inside a $13 \mathrm{~mm}$ O.D. stainless steel tube. The space between the steel and Teflon tubes was filled with deionized water. The steel tube was wrapped with heating tape (VWR), and the external temperature was maintained at $40^{\circ} \mathrm{C}$ using a temperature controller and a thermocouple. After exiting the humidifier, the aerosol stream was passed through a $3 \mathrm{~m}, 13 \mathrm{~mm}$ OD PFA tube to allow $\sim 12 \mathrm{~s}$ equilibration with water vapor before entering the reactor. The $\mathrm{RH}$ of the equilibrated $\mathrm{N}_{2}$ /aerosol stream was monitored at the inlet to the reaction chamber with a hygrometer (Vaisala).

Aerosol size distributions were continuously obtained by a DMA and CPC in series, which in most experiments sampled the particle stream exiting the photocell. This configuration was chosen to provide a better measure of reactor aerosol concentrations, since small mass losses were associated with particles impacting as they passed through a $90^{\circ}$ bend at the reactor entrance. The coated aerosol populations exhibited a near log-normal size distribution not distinguishable from that of the pure salt particle population, with a typical geometric standard deviation of 2.0. The coated aerosols had a typical mean surface-weighted particle radius $\mathrm{r}_{p} \sim 120 \mathrm{~nm}$, and total aerosol surface area was typically between $4 \times 10^{-4}-1 \times 10^{-3} \mathrm{~cm}^{2} \mathrm{~cm}^{-3}$. Typical volumeweighted particle radii for the pure palmitic acid aerosols were varied from $85-220 \mathrm{~nm}$, with a typical geometric standard deviation of 1.25 .

\subsection{Continuous flow photocell reactor}

The reactor consisted of a quartz photocell $25 \mathrm{~cm}$ long and $5 \mathrm{~cm}$ in diameter with a $1 \mathrm{~cm}$ inner sleeve containing an ozone-free $\mathrm{Hg}$ pen-ray lamp (Jelight, $254 \mathrm{~nm}$ ). $\mathrm{OH}$ was formed from the reaction of $\mathrm{O}\left({ }^{1} \mathrm{D}\right)$ with water, where $\mathrm{O}\left({ }^{1} \mathrm{D}\right)$ is produced by ozone photolysis. $\mathrm{O}_{3}$ was generated continuously during experiments by flowing a mixture of $\mathrm{O}_{2}$ and $\mathrm{N}_{2}$ through a photocell containing a $\mathrm{Hg}$ pen-ray lamp (UVP) operating at $185 \mathrm{~nm}$. The $\mathrm{O}_{3}$ concentration of the outlet stream was monitored using a UV absorption cell equipped with another $\mathrm{Hg}$ pen-ray lamp (Jelight) coated to primarily emit $254 \mathrm{~nm}$, a $254 \mathrm{~nm}$ interference filter, and a photodiode (Thorlabs). The desired $\mathrm{O}_{3}$ concentration was achieved by adjusting the relative concentrations of $\mathrm{O}_{2}$ and $\mathrm{N}_{2}$. The RHequilibrated aerosol stream was mixed with the $\mathrm{O}_{3} / \mathrm{N}_{2} / \mathrm{O}_{2}$ mixture at the entrance to the photocell reactor. The initial concentration of $\mathrm{O}_{3}$ in the photocell ranged from 0.2$25 \mathrm{ppm} . \mathrm{O}_{2}$ mixing ratios were varied from $\sim 2 \%-20 \%$. Additional experiments were performed in which $\mathrm{O}_{2}$ was maintained at $20 \%$ across a range of $\mathrm{OH}$ exposures in order to elucidate any effects of $\mathrm{O}_{2}$ on particle chemistry.

$\mathrm{OH}$ concentrations in the photoreactor were inferred via calibration experiments using the observed loss of $\mathrm{SO}_{2}$ and the recommended rate constant for the reaction of $\mathrm{SO}_{2}$ with OH (DeMore et al., 1997). Sample cylinders of $50 \mathrm{ppm} \mathrm{SO}_{2}$ in $\mathrm{N}_{2}$ were prepared from a pure $\mathrm{SO}_{2}$ cylinder (Matheson), and 5-10 sccm of this mixture was diluted in 1.4-1.6 slpm humidified $\mathrm{N}_{2}$ in order to create 4.5$7.5 \times 10^{12} \mathrm{molec}^{-3} \mathrm{SO}_{2}$ and $16 \% \mathrm{RH}$ in the flow tube. The loss of $\mathrm{SO}_{2}$ in the presence of UV light was monitored by CIMS as a function of initial $\mathrm{O}_{3}$ concentration. The observed loss was compared to the output of a photochemical model that includes ozone photolysis to yield $\mathrm{O}\left({ }^{1} \mathrm{D}\right)$ and its reaction with $\mathrm{H}_{2} \mathrm{O}$, as well as several $\mathrm{HO}_{\mathrm{x}}$ cycling reactions, $\mathrm{HO}_{\mathrm{x}}$ self-reactions, a diffusion-limited loss of $\mathrm{OH}$ on the reactor walls, and a loss of $\mathrm{OH}$ on particles. The latter process was disabled when comparing to $\mathrm{SO}_{2}$ titrations which were performed in the absence of particles. The observed $\mathrm{SO}_{2}$ reactivity was used to constrain only two parameters: the photolytic rate constant for $\mathrm{O}_{3}$ and the diffusion-limited rate constant for $\mathrm{OH}$ loss at the reactor walls. Adjusting the $\mathrm{O}_{3}$ photolytic rate constant alone was sufficient to give reasonably good agreement between model and data. Including the $\mathrm{OH}$ wall loss parameter improved the model's ability to reproduce the curvature in the observed $\mathrm{SO}_{2}$ loss (and thus $\mathrm{OH}$ concentration) versus $\mathrm{O}_{3}$ mixing ratio. The model, which will be published as supplemental information, was 


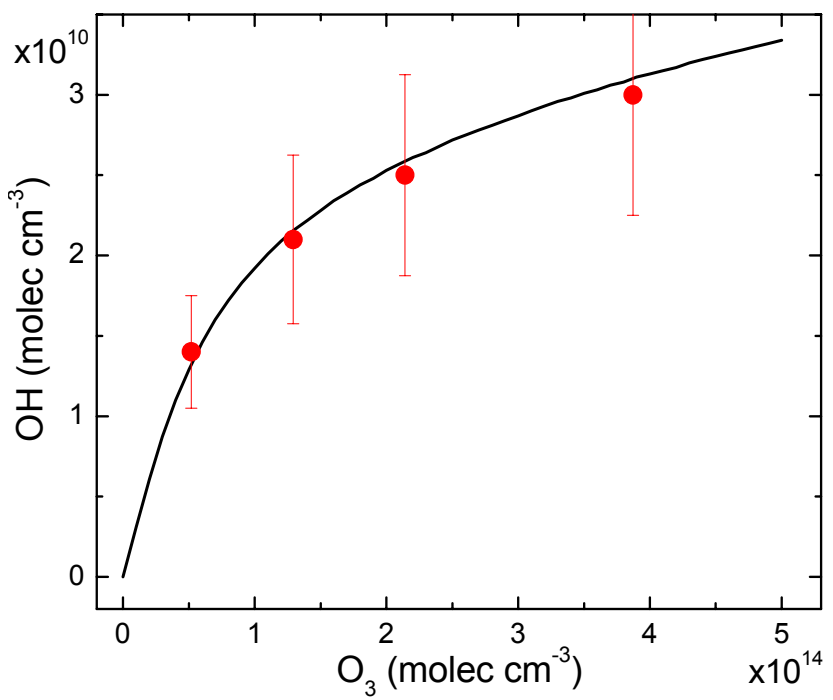

Fig. 2. OH predicted by the photochemical box model (line) compared to that calculated from $\mathrm{SO}_{2}$ loss experiments (circles). Error bars represent $25 \%$ uncertainty in $\mathrm{OH}$ calibration data.

then used to predict reactor $\mathrm{OH}$ concentrations and PA loss simultaneously for a given $\mathrm{O}_{3}$ concentration and exposure time. Figure 2 shows the $\mathrm{OH}$ predicted by the model and that inferred from the $\mathrm{SO}_{2}$ loss in the reactor as a function of the initial $\mathrm{O}_{3}$ mixing ratio.

\subsection{CIMS detection of reactants and products}

The chemical ionization mass spectrometer (CIMS) system and the detection method for organic acids has been described in detail previously (McNeill et al., 2006, 2007). Palmitic acid and its $\mathrm{OH}$-oxidation products containing a carboxylic acid functionality are detected with $\mathrm{I}^{-} \cdot\left(\mathrm{H}_{2} \mathrm{O}\right)$ as the reagent ion undergoing ligand-switching reactions. For example, palmitic acid was monitored as the cluster with $\mathrm{I}^{-}\left(\mathrm{I}^{-} \cdot \mathrm{C}_{16} \mathrm{H}_{32} \mathrm{O}_{2}\right)$ at $383 \mathrm{amu}$. In this study, organics in the particle phase were volatilized for detection by thermal desorption in a continuous flow heated inlet (Hearn and Smith, 2004; McNeill et al., 2007). For comparison purposes, in a few experiments with PA-coated $\mathrm{NaCl}$ particles, we used a novel impactor coupled to the CIMS inlet currently under development in our group. Particles are collected on a surface that is subsequently heated. Similar kinetics and products were observed with both detection methods.

Detection of the components occurred at the exit of a $23 \mathrm{~cm}$ long, $1.27 \mathrm{~cm}$ O.D. PFA tube wrapped with heating tape (VWR). This inlet's temperature was monitored and controlled using a thermocouple and temperature controller (Omega). The response of the signal to varying pure particle aerosol mass concentration or the coated particle aerosol surface area was linear, with a sensitivity of $268 \pm 34 \mathrm{~Hz}_{\mu \mathrm{g}}-1 \mathrm{~m}^{3}$. Based on various calibrations we sus-

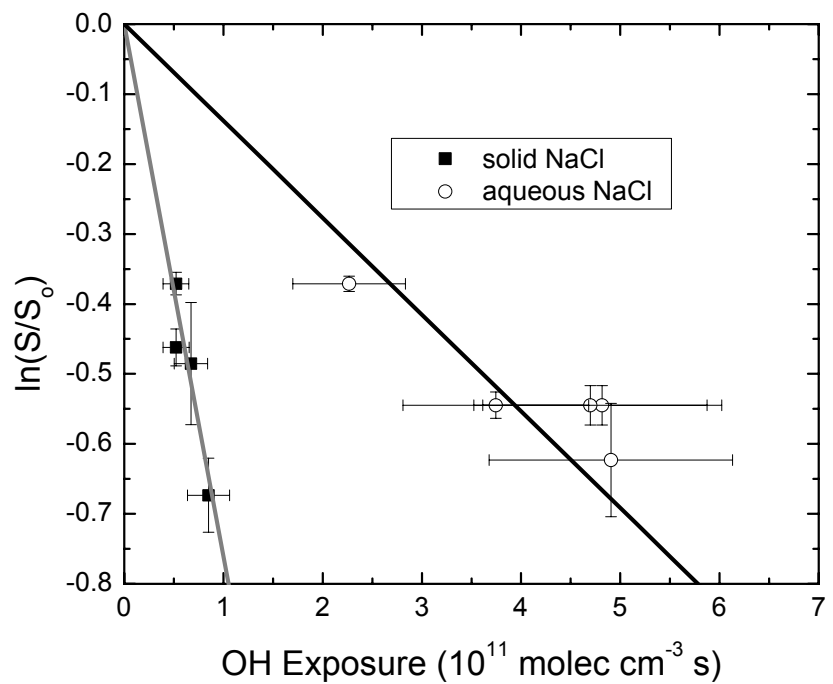

Fig. 3. Loss of palmitic acid on dry (squares) and aqueous (circles) $\mathrm{NaCl}$ particles as a function of $\mathrm{OH}$ exposure. Lines represent the error-weighted linear least squares fits to the experimental data. $\mathrm{RH}$ for aqueous experiments is $>80 \%$.

pect all carboxylic acids are theoretically detected with a similar sensitivity, to within a factor of 2 , for a given water vapor concentration, but no attempt was made to calibrate to invidual products and thus absolute product yields are not derived. $\mathrm{SO}_{2}$ was detected using $\mathrm{SF}_{6}^{-}$and a reduced chemical ionization reaction time to minimize the effect of $\mathrm{O}_{3}$. Ozone reacts with $\mathrm{SF}_{6}^{-}$, but at a slower rate than $\mathrm{SO}_{2}$. In addition, high water vapor conditions were also precluded when using $\mathrm{SF}_{6}^{-}$.

Experiments were conducted by first aquiring an initial mass spectrometer signal for the given particle and $\mathrm{O}_{3}$ concentrations, in the absence of UV light. The lamp was then turned on, causing a decrease in the palmitic acid signal and an increase in signals at masses corresponding to oxidation products. Background signals in the absence of particles were measured at the beginning and end of each experiment. To obtain mechanistic information, $\mathrm{O}_{3}$ concentrations and/or reactor residence time (and thus $\mathrm{OH}$ concentration and exposure) were varied. Depending on the experiment, total flow rate varied from 1.7 to $3 \mathrm{slpm}$, corresponding to a residence time in the photocell of 10 to $17 \mathrm{~s}$. For all experiments except volatile product studies and the $\mathrm{SO}_{2}$ calibration of the photoreactor, the reactor effluent was passed through a diffusion tube packed with Carulite $\mathrm{O}_{3}$-scrubbing catalyst (Caruschem) before entering the heated CIMS inlet. 


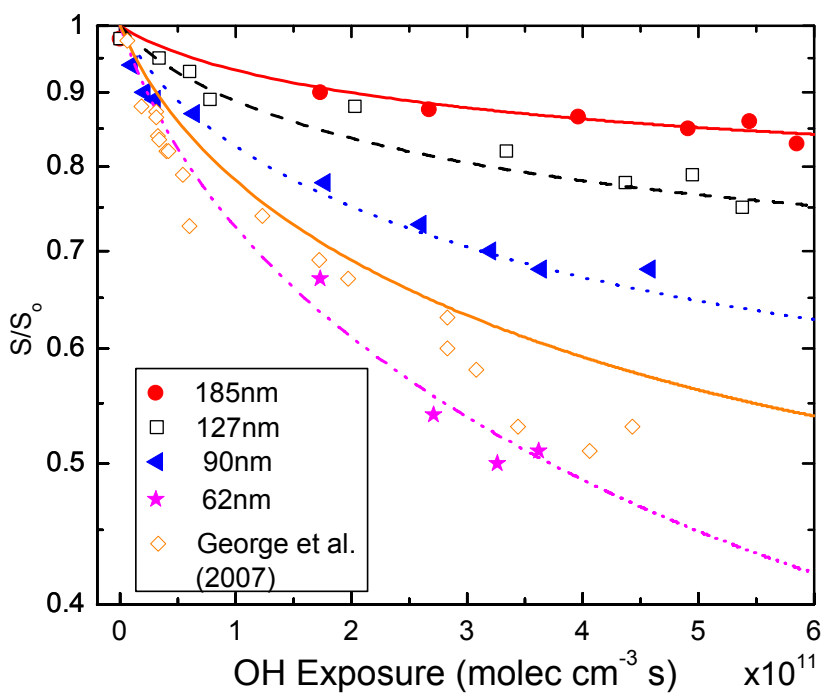

Fig. 4. Palmitic acid remaining for pure particles of four different sizes, $185 \mathrm{~nm}(\bullet), 127 \mathrm{~nm}(\square), 90 \mathrm{~nm}(\triangleleft)$, and $62 \mathrm{~nm}(\star)$ versus $\mathrm{OH}$ exposure. Data shown as diamonds are those of George, et al. (2007). Symbols represent experimental data and the lines represent model predictions for the respective sizes.

\section{Results}

\subsection{Kinetics of palmitic acid film oxidation}

For both solid and aqueous $\mathrm{NaCl}$ particles, we observed a prompt decrease in palmitic acid signal when the UV lamp was turned on in the presence of $\mathrm{O}_{3}$ and $\mathrm{H}_{2} \mathrm{O}$. The $\mathrm{OH}$ concentration and residence time in the flow tube were varied to examine the extent of loss as a function of $\mathrm{OH}$ exposure $([\mathrm{OH}] \times \mathrm{t})$. Due to experimental limitations on flow ratios, only a small range in $\mathrm{OH}$ exposure could be examined for each aerosol type. Figure 3 shows palmitic acid loss data for the coated particles. The fraction of PA remaining relative to the baseline PA signal is shown on a log scale as a function of $\mathrm{OH}$ exposure. Loss data are shown for solid particles (squares) and particles equilibrated at $\mathrm{RH}>80 \%$ which we assume are aqueous (circles). A substantial difference exists in the $\mathrm{OH}$ oxidation kinetics of PA on solid and aqueous particles, with $\mathrm{PA}$ on solid $\mathrm{NaCl}$ particles exhibiting greater loss at lower $\mathrm{OH}$ exposure than observed for PA on aqueous particles.

Assuming a heterogeneous reaction between $\mathrm{OH}$ and $\mathrm{PA}$ at the surface of the coated particles, the loss rate of PA can be expressed as:

$\frac{d[\mathrm{PA}]_{\text {surf }}}{d t}=-k^{I I}[\mathrm{OH}][\mathrm{PA}]_{\text {surf }}$

where $k^{I I}$ is the second-order rate coefficient, and $[P A]_{\text {surf }}$ is the surface concentration of palmitic acid, in molec $\mathrm{cm}^{-2}$. A plot of the natural $\log$ of the ratio of PA signal at each $\mathrm{OH}$ exposure to the PA signal in the abscence of $\mathrm{OH}, \mathrm{S} / \mathrm{S}_{0}$, is fit



Fig. 5. Relative change in initial radius for pure palmitic acid particles of two different sizes, $160 \mathrm{~nm}(\mathrm{O})$, and $90 \mathrm{~nm}(4)$. Symbols represent experimental data and the lines represent model predictions for the respective sizes.

reasonably well with a straight line forced through the origin $\left(\mathrm{R}^{2} \sim 0.86-0.96\right) . \mathrm{S} / \mathrm{S}_{0}$ is proportional to $[P A]_{\text {surf }} /[P A]_{\text {surf }, 0}$ since the surface area to mass ratio for these particles is constant (in the case of the coated particles) or nearly so (for pure PA particles). The slope of the error-weighted linear least-squares fit yields the observed pseudo-first-order rate coefficient, $k^{I}=k^{I I}[\mathrm{OH}]$, which is then related to the reaction probability for an encounter between $\mathrm{OH}(\mathrm{g})$ and $\mathrm{PA}(\mathrm{s})$ in the free molecular regime, $\gamma^{\mathrm{OH}}$ according to:

$\gamma^{\mathrm{OH}}=\frac{4 k^{I}}{\sigma_{\mathrm{PA}} \omega_{\mathrm{OH}}}$

where $\sigma_{\mathrm{PA}}$ is the molecular cross-section of PA at the surface and $\omega_{\mathrm{OH}}$ is the thermal velocity of $\mathrm{OH}$. In this study we assume $\sigma_{\mathrm{PA}} \sim 2 \times 10^{-15} \mathrm{~cm}^{2} /$ molec based on Langmuir trough measurements of palmitic acid films on water (Adam, 1921). Applying this equation and correcting for the effects of gas-phase diffusion and transition regime effects for Kn $\sim 1$ (Fuchs and Sutugin, 1970) yields reaction probabilities of $\gamma^{\mathrm{OH}} \sim 0.05 \pm 0.01$ for PA on aqueous particles and $\gamma^{\mathrm{OH}} \sim 0.3$ $+0.1 /-0.05$ for PA on solid salt particles. The reported uncertainty stems from propagating a $\pm 25 \%$ uncertainty in $\mathrm{OH}$ concentrations through equation (2) and the transition regime correction. These reaction probabilities assume that the PA signal arising from these coated particles is largely determined by surface area; thus, the surface-weighted particle radius was used to determine the transition regime correction. 


\subsection{Kinetics of pure Palmitic Acid Particle oxidation}

In Fig. 4, the fraction of PA remaining relative to the baseline PA signal, $\mathrm{S} / \mathrm{S}_{0}$, is shown on a log scale as a function of $\mathrm{OH}$ exposure for four different initial mean volume weighted particle sizes: $r_{0}=62 \mathrm{~nm}, 90 \mathrm{~nm}, 127 \mathrm{~nm}$, and $185 \mathrm{~nm}$. For all sizes the PA signal decreases with increasing exposure. The relative loss increases as mean size decreases. This behavior is consistent with a gas-surface mechanism, since the surface area-to-volume ratio increases with decreasing particle size. The signal ratio in both log and linear space is nonlinear with $\mathrm{OH}$ exposure. This nonlinearity is most evident in the small particle data, though it is clear that psuedo-first order kinetics is not appropriate for the larger sizes either. With no mechanism to refresh the surface, the loss rate of condensed-phase PA due to heterogeneous oxidation is expected to slow with increased $\mathrm{OH}$ exposure due to the decreased probability of $\mathrm{OH}$ reacting with PA upon collision with the particle (Ammann, et al., 2003). However, the deceleration appears to be more prompt for PA particles than for liquid BES particles (George et al., 2007). For comparison, we have included the BES oxidation data from George, et al. (2007) shown as diamonds. In addition to the observed nonlinearity, far more PA is lost than would be present at the surface, and thus PA originally below the surface layer is reacting with $\mathrm{OH}$. That is, $\mathrm{OH}$ is penetrating into the bulk of the particle, or sub-surface layers are being exposed to $\mathrm{OH}$.

Figure 5 shows the relative change in particle radius as a function of $\mathrm{OH}$ exposure for pure PA particles with initial mean volume weighted particle radii $r_{0}=160 \mathrm{~nm}$ and $90 \mathrm{~nm}$. After an $\mathrm{OH}$ exposure of $\sim 3 \times 10^{11} \mathrm{molec} \mathrm{cm}^{-3} \mathrm{~s}$, the absolute change in radius was $\sim 9 \mathrm{~nm}$ and $6.4 \mathrm{~nm}$ for the initial radii of $90 \mathrm{~nm}$ and $160 \mathrm{~nm}$, respectively.

\subsection{Oxidation products}

Mass spectra were taken in the presence and abscence of both $\mathrm{OH}$ and particles in order to examine the types of products generated during $\mathrm{OH}$ oxidation. In an attempt to account for species that might be produced from $\mathrm{OH}$ reaction on the flow tube walls or from the fragmentation of PA itself, we took three different types of spectra: 1) $\mathrm{OH}$ and PA particles present, 2) $\mathrm{OH}$ present but no PA particles, 3) no $\mathrm{OH}$ but PA particles present. Figure 6 shows the result of subtracting spectra types 2 and 3 from spectrum type 1. Peaks corresponding to species with both lower and higher molecular weights than PA remain positive in this difference spectrum. The exception is a peak at $399 \mathrm{amu}$, which appeared when PA particles were exposed to $\mathrm{O}_{3}$ only but increased above this baseline with $\mathrm{OH}$ (see Fig. 7). Most notable in this difference spectrum is the dominant peak corresponding to formic acid, $\mathrm{I}^{-} \cdot(\mathrm{HCOOH})$, located at $173 \mathrm{amu}$, and the envelope of peaks between 200-300 amu (see inset) that correspond to oxidation products with molecular weights lower than that of PA. Our ion chemistry is largely specific to com- pounds containing carboxylic acid groups, i.e. aldehydes or ketones are not detected unless a carboxylic acid moeity is present.

To approximately evaluate the gas-particle partitioning of the oxidation products, spectra were also taken during oxidation, but without thermal desorption at the inlet. All oxidation products detected at masses below $\sim 300$ amu were also observed in the absence of heating, that is, they were likely gas-phase products. Notable particle-bound products (i.e. those observed only during thermal desorption) include those detected at $397.2 \mathrm{amu}$ and $399.2 \mathrm{amu}$ (14 amu and $16 \mathrm{amu}$ higher than the palmitic acid signal, respectively). Figure 7 shows the development of these particle-bound product signals with $\mathrm{OH}$ exposure. These product signals have been corrected for background signals in the absence of $\mathrm{OH}$.

\section{Analysis and interpretation}

In the following section, we give a brief interpretation of the $\mathrm{OH}$ oxidation kinetics of palmitic acid coatings on salt particles and then connect this data to the kinetics of pure palmitic acid particle oxidation. The uncertainty in our $\mathrm{OH}$ exposure coordinate in both cases is likely the largest contributor to the total uncertainty of our measurements. Our $\mathrm{SO}_{2}$ titrations, essentially a relative rate experiment, provided $[\mathrm{OH}] \times \mathrm{t}$ estimates that were reproducible to within $\sim 25 \%$. This level of uncertainty has a fairly substantial effect on the derived reaction probabilities, in part because of the nonlinearity in the diffusion correction as the measured reaction probability increases. Additional uncertainties stem from using the model to predict $\mathrm{OH}$ at $\mathrm{RH}$ greater than those of the $\mathrm{SO}_{2}$ titration experiments. This issue is especially important for the PA coatings on aqueous salt particles. Thus, we have much more confidence in our pure palmitc acid oxidation experiments and the PA coated dry salt experiments, but we feel able to conclude that the observed difference between kinetics on solid and aqueous particles is significant.

\subsection{Palmitic acid oxidation on solid and aqueous salt parti- cles}

We infer a reaction probability, $\gamma^{\mathrm{OH}}$, of $\sim 0.3+0.1 /-0.05$ for palmitic acid molecules on the surface of crystalline salt particles. This value is in general agreement with the lower limit of 0.2 determined by Bertram, et al. (2001) using a flow tube with paraffin wax-coated walls. To our knowledge, our data are the first to examine the reactivity of $\mathrm{OH}$ with surfacebound palmitic acid on submicron salt particles.

It is clear from Fig. 3 that the oxidation of PA in aqueous salt particles is slower by a factor of $\sim 5$ or more than on solid particles. Even though significant uncertainty exists in the $\mathrm{OH}$ exposure at high $\mathrm{RH}$ because we were unable to calibrate for $\mathrm{OH}$ at $89 \% \mathrm{RH}$, it seems unlikely that the inferred $\mathrm{OH}$ is too high by a factor of five. At this time, we 


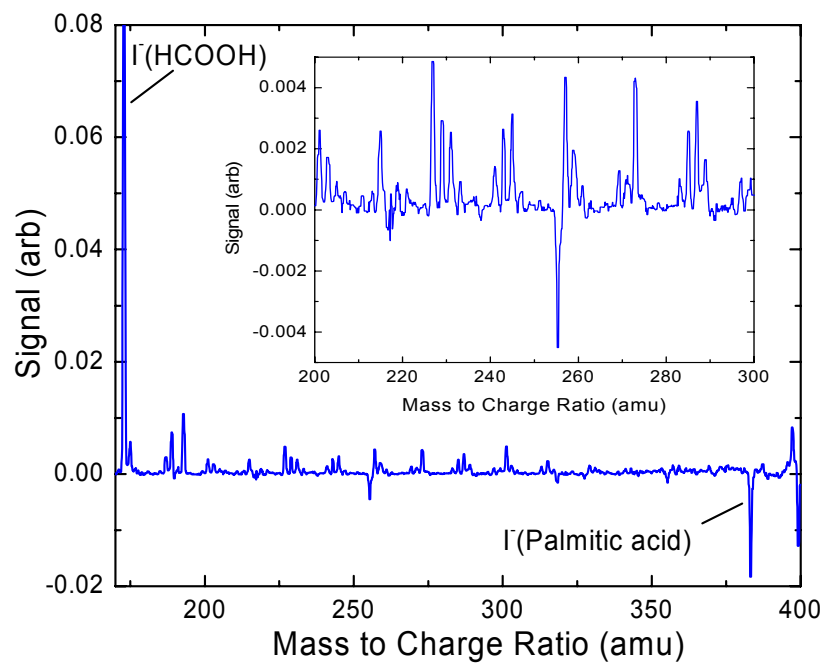

Fig. 6. Mass spectra showing smaller-molecular-weight products from palmitic acid oxidation by $\mathrm{OH}$. Inset is the magnification of the spectrum from 200 to $300 \mathrm{~m} / \mathrm{z}$.

can only speculate as to the reasons for this difference. On the one hand, the PA in aqueous particles may not be distributed entirely at the surface but exist in phase-separated agglomerates not easily accessed by $\mathrm{OH}$. In this case, our model represented by equations 1 and 2 is invalid. On the other hand, we have indirect evidence from the inefficient hydrolysis of $\mathrm{N}_{2} \mathrm{O}_{5}$ on these PA-coated aqueous particles that would suggest a significant coating of PA at the surface (McNeill et al., 2006, 2007). If PA is at the surface of these aqueous salt particles, a possible explanation for the reduced efficiency of $\mathrm{OH}$ oxidation might be due to the orientation of PA relative to the gas-phase. PA, a surfaceactive fatty acid, may orient itself at the gas-aerosol interface in an inverted micelle configuration, in which case the attacking $\mathrm{OH}$ would most likely collide with a primary carbon at the end of the hydrocarbon tail (Myers, 2006; Gill et al., 1983; Ellison et al., 1999). Hydrogen extraction from a primary carbon is much less efficient than secondary or tertiary carbons in the gas-phase; for $\mathrm{OH}$ reacting with ethane in the gas phase, the bimolecular rate constant at $\sim 300 \mathrm{~K}$ is $2.74 \times 10^{-13} \mathrm{~cm}^{3} \mathrm{molec}^{-1} \mathrm{~s}^{-1}$, while for $\mathrm{OH}+n$-butane, it is $\sim 2.76 \times 10^{-12} \mathrm{~cm}^{3} \mathrm{molec}^{-1} \mathrm{~s}^{-1}$ (Atkinson, 1986). Perhaps a similar effect is present in gas-surface reactions. Nevertheless, the data shown here are, to our knowledge, the first of their kind. More work is needed before it will be possible to draw strong conclusions about the effects of particle phase and surface morphology on the $\mathrm{OH}$ oxidation efficiency of surface-bound organics.

\subsection{Oxidation of pure palmitic acid particles}

We presume, as have others, that the initial steps in the mechanism of particle-phase $\mathrm{OH}$ oxidation are analogous to gas-

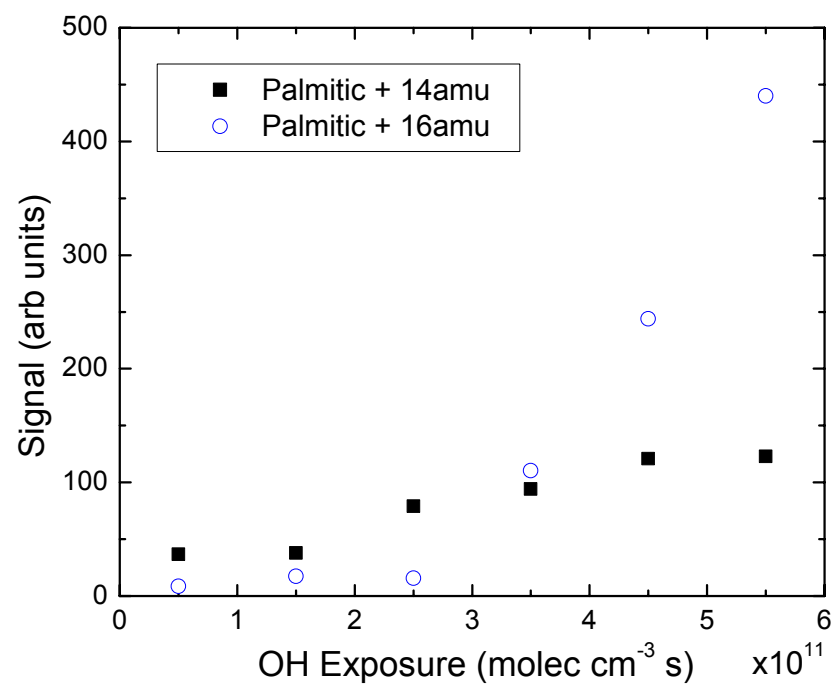

Fig. 7. Plot showing two palmitic acid products in particle phase, palmitic acid + 14 amu (keto-acid, $\mathbf{0}$ ), and PA + 16 amu (hydroxy acid, O), for an $\mathrm{OH}$ exposure of $4.7 \times 10^{11}$ molec $\mathrm{sm}^{-3}$.

phase hydrogen atom abstraction (Molina et al., 2004; Eliason et al., 2004; George et al., 2007). Given the levels of $\mathrm{O}_{2}$ in our reactor, the likely result of $\mathrm{OH}$ reacting with a surfacebound PA is $\mathrm{O}_{2}$ addition to the alkyl radical forming an organic peroxy radical $\left(\mathrm{RO}_{2}\right)$. We saw no dependence on $\mathrm{O}_{2}$ concentration for the range used in our experiments. The fate of this $\mathrm{RO}_{2}$ could be reaction with $\mathrm{HO}_{2}$ to form organic hydroperoxides (ROOH), or self-reaction to either yield stable hydroxy and carbonyl products or an alkoxy (RO) radical. The alkoxy radical can then isomerize and react with $\mathrm{O}_{2}$ to form a hydroxyperoxy radical. Alternatively, the RO can react with $\mathrm{O}_{2}$ to form a stable carbonyl product or undergo bond scission to yield smaller molecular weight fragments. This latter path is the most likely to lead to mass loss by volatilization. Recently, secondary condensed-phase chemistry between the radical oxidation products and the primary particle component has been proposed to explain $\mathrm{Cl}$ radical - BES reaction probabilities that exceed unity (Hearn et al., 2007). If secondary chemistry occurs, it is likely to occur via the higher energy alkoxy radical than $\mathrm{RO}_{2}$.

Our observation of volatile, lower-molecular-weight products from the $\mathrm{OH}$ oxidation of palmitic acid is qualitatively consistent with Molina et al. (2004), who observed $\mathrm{OH}-$ initiated volatilization of SAMs and macroscopic solid organic surfaces, and with the stearic acid oxidation studies of Vlasenko et al. (2008). We also previously observed gasphase products upon exposure of thin films of oleate to $\mathrm{OH}$ (McNeill et al., 2007). Our observations of the reactor effluent composition and the decrease in mobility diameter with $\mathrm{OH}$ exposure suggest mass loss by volatilization, consistent with a mechanism that includes alkoxy radical formation followed by bond scission. Both scission and non-scission $\mathrm{OH}$ 


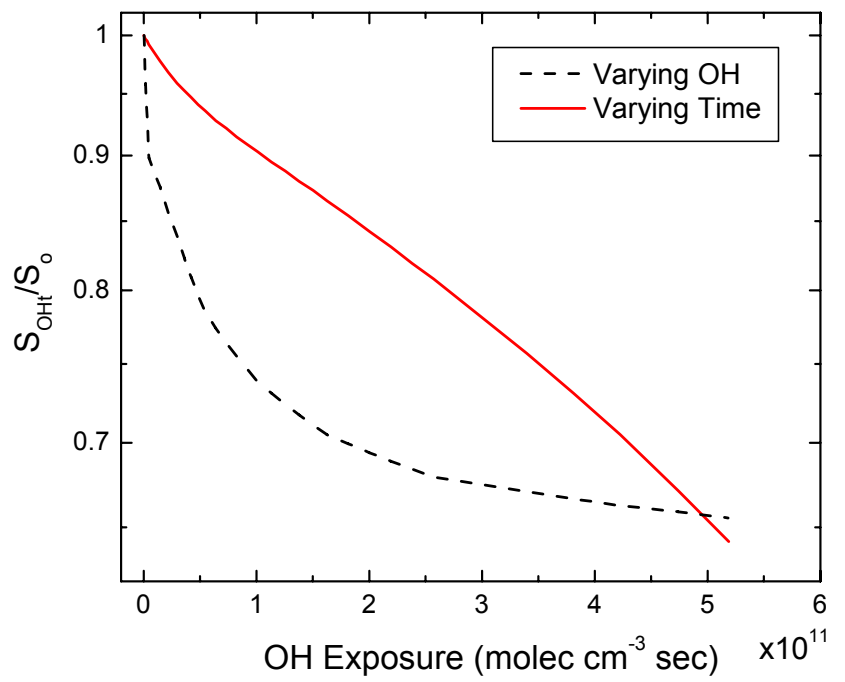

Fig. 8. Model results for palmitic acid remaining versus $\mathrm{OH}$ exposure calculated using two different methods, varying $\mathrm{OH}$ concentration with constant reaction time (dashed line), and varying reaction time keeping $\mathrm{OH}$ constant (solid line)

oxidation products might additionally undergo further oxidation partly via the scission pathway. George et al. (2007) and Hearn and Smith (2007) observed that ketone and alcohols were the dominant products for BES oxidation. While some volatilization was inferred through particle size changes in the study by George et al. (2007), no direct observation of lower-molecular-weight gas-phase species were made in either of these studies. As shown in Fig. 7, except for the highest $\mathrm{OH}$ exposures, our inferred ketoacid oxidation product species at $397.2 \mathrm{amu}$ was present in greater abundance than the hydroxyacid at 399.2 amu. This suggests that alkyl peroxy radical self-reaction to form a carbonyl and alcohol is not the dominant reaction pathway in this system at low $\mathrm{OH}$ exposures. See, for example, pathway (2) in George, et al. (2007).

The $\mathrm{OH}$ oxidation of palmitic acid in single component particles occurs well beyond the initial surface layer given that one monolayer on a $125 \mathrm{~nm}$ radius particle accounts for $\sim 5 \%$ by mole of the particle content. Given the high reactivity of $\mathrm{OH}$ with aliphatic compounds, its reacto-diffusive length will be very short in a liquid particle, $\sim 1 \mathrm{~nm}$, and even shorter if the particle is a solid (due to a higher resistance to diffusion in the solid). Thus, the observed extent of oxidation is not expected unless there is some mechanism to refresh the surface (i.e. volatilization) or to propogate the oxidation into the bulk (i.e. secondary condensed phase radical chemistry). An alternative explanation is that the palmitic acid particles exist as a supercooled liquid, i.e. that the surface is refreshed via mixing within the particle and/or $\mathrm{OH}$ can undergo substantial diffusion into the particle. However, a model based on reactive uptake of $\mathrm{OH}$ to a liquid particle, that includes the assumption that every $\mathrm{OH}$ colliding with the particle surface would encounter the initial particle component (Worsnop et al., 2002), does not reproduce the majority of our data well.

We developed a numerical model in order to interpret our results in the context of a fast surface reaction, secondary condensed phase chemistry, and mass loss by volatilization. The unique aspects of this model are that it assumes palmitic acid reacts with $\mathrm{OH}$ only at the particle surface and it requires no a priori assumptions about particle phase or instantaneous mixing. Processes included are: 1) the reaction of $\mathrm{OH}$ with PA at the surface, 2) secondary reactions between oxidation products and unreacted PA, and 3) a surface renewal process which exposes fresh PA to the surface. In addition, we allow particle size to change in the model for comparison to observed electric mobility size changes during oxidation..

The differential equation governing the fractional surface coverage of $\mathrm{PA}\left(\theta_{\mathrm{PA}}\right)$ is:

$$
\frac{d \theta_{\mathrm{PA}}}{d t}=-k_{1}[\mathrm{OH}] \theta_{\mathrm{PA}}-\mathrm{k}_{2}\left(1-\theta_{\mathrm{PA}}\right) \theta_{\mathrm{PA}}+\mathrm{k}_{\mathrm{ren}}\left(1-\theta_{\mathrm{PA}}\right)
$$

where $\mathrm{k}_{1}$ is related to $\mathrm{k}^{I}$ described in Eq. (2) in that $\mathrm{k}^{I}=\mathrm{k}_{1}[\mathrm{OH}]$ in the free-molecular regime. We account for transition regime effects in the calculation of $\mathrm{k}_{1}$, and $k_{2}$ is the second-order rate constant for secondary reactions between PA and oxidation products in the surface layer. The surface concentration of products is simply $1-\theta_{\mathrm{PA}}$. We assume the total number of surface sites does not change over the course of an experiment. The renewal of the surface is taken to be first order in the surface concentration of products, with a rate constant $k_{\text {ren }}$. Possible physical interpretations of this renewal process include the volatilzation of products which in turn exposes underlying PA, or a liquification of the surface layer into which subsurface $\mathrm{PA}$ would dissolve and $\mathrm{OH}$ would diffuse.

The relevant quantity for comparing model output to the experimental results is the fraction of PA remaining after exposure $\left(n_{\mathrm{PA}} / n_{\mathrm{PA}, 0}\right)$ :

$\frac{d\left(n_{\mathrm{PA}} / n_{\mathrm{PA}, 0}\right)}{d t}=\frac{1}{n_{\mathrm{PA}, 0}} \frac{3}{r \sigma}\left(-k_{1}[\mathrm{OH}] \theta_{\mathrm{PA}}-\mathrm{k}_{2}\left(1-\theta_{\mathrm{PA}}\right) \theta_{\mathrm{PA}}\right)$

Note that vaporization of the oxidation products does not directly reduce the total PA concentration in the particle. Particle size change due to vaporization is calculated according to

$$
\frac{d r}{d t}=\chi_{\mathrm{vap}} \frac{r_{0}^{3}}{3 r^{2}} \frac{d\left(n_{\mathrm{PA}} / n_{\mathrm{PA}, 0}\right)}{d t}
$$

where $r_{0}$ is the initial particle radius, and $\chi_{\text {vap }}$ is a factor meant to relate the combined effects of density changes and mass loss by volatilization to the rate of palmitic acid oxidation (Katrib et al., 2005; George et al., 2007). Equations (3)(5) and those governing the production and destruction of $\mathrm{OH}$ are solved simultaneously with a fixed integration time equal to the photoreactor residence time. Inputs to the model are 
$\mathrm{RH}, \mathrm{O}_{3}$, particle surface area, and volume-weighted $\mathrm{r}_{p}$. Initially, the surface is assumed to consist of palmitic acid only $\left(\theta_{\mathrm{PA}}=1\right)$. The model is compared to the observed palmitic acid loss, and $\gamma^{\mathrm{OH}}, \mathrm{k}_{2}, \mathrm{k}_{\text {ren }}$, and $\chi_{\text {vap }}$ are adjusted to minimize the model-measurement difference.

Model simulations are shown as lines in Figs. 4 and 5. Both the PA loss observed for all particle sizes with the CIMS and the observed mobility size change can be simulated well with a single set of parameters: $\gamma^{\mathrm{OH}}=1, \mathrm{k}_{2}=0.22 \mathrm{~s}^{-1}$, $\mathrm{k}_{\mathrm{ren}}=0.35 \mathrm{~s}^{-1}$, and $\chi_{\text {vap }}=0.9$. At short $\mathrm{OH}$ exposures, the model is most sensitive to the choice of $\gamma^{\mathrm{OH}}$ and $\mathrm{k}_{2}$. A value of $\gamma^{\mathrm{OH}}<1$ can be used, but must be compensated for by increasing $\mathrm{k}_{2}$. This compensation works only within a narrow range of $\gamma^{\mathrm{OH}}$. For example, setting $\gamma^{\mathrm{OH}}=0.5$ and $\mathrm{k}_{2}=0.4 \mathrm{~s}^{-1}$ can grossly reproduce the data but the modeled curvature is too steep at low $\mathrm{OH}$ exposures and too shallow at high $\mathrm{OH}$ exposures. At larger $\mathrm{OH}$ exposures, the surface renewal process becomes rate-limiting. The PA loss observed with the CIMS is fairly insensitive to the value of $\chi_{\text {vap }}$, which can range from $\sim 0.75-1$ without significant loss of agreement. This parameter controls the rate of particle size change, and while a decrease in size does accelerate the oxidation of the surface by decreasing the gas-phase diffusion limitation, the relative size change is not large enough to compete with the surface renewal term except in the smallest sizes examined $\left(\mathrm{r}_{\mathrm{p}} \sim 60 \mathrm{~nm}\right)$. The mobility size change data, however, are very sensitive to $\chi_{\text {vap }}$, and require $\chi_{\text {vap }} \sim 0.9$.

For comparison, we applied our model to the data of George, et al. (2007) using only their reported initial volumeweighted radius. As shown in Fig. 4, the model consistently underestimates their observed extent of reaction for the same model parameters that best match our data. A larger surface renewal term and a slightly larger secondary chemistry term are required to match the George, et al. (2007) data. We attribute these differences to the likelihood that PA particles are solids while BES particles are liquids. Therefore, in BES particles $\mathrm{OH}$ will have a greater reacto-diffusive length and the surface may be refreshed by mixing within the particle.

Laboratory studies of atmospheric heterogeneous chemistry face a challenge when aiming for close replication of atmospheric conditions given the very low oxidant levels (sub pptv) and long interaction times (days to weeks). The exposure coordinate is used to analyze kinetics under the assumption that the product of oxidant concentration and interaction time allows for the direct comparison of low-concentration and long-time conditions with high-concentration and shorttime conditions. In Fig. 8, we show the results from two different versions of our model described above. In one simulation, we fixed the $\mathrm{OH}$ concentration while vaying the interaction time over which the rate equations were integrated. In the other simulation, we fixed the integration time over which the rate equations were integrated while varying the $\mathrm{OH}$ concentration. The implication is that, at least for the reaction mechanism in our model, the exposure coordinate may not allow direct extrapolation to atmospheric conditions. By systematically eliminating various processes from the model we find that it is the combination of surface renewal and secondary chemistry that gives rise to the difference in model output along the $\mathrm{OH}$ exposure coordinate for the two scenarios.

\subsection{Physical interpretation of model parameters}

The combined mass spectral and mobility size data suggest that for pure palmitic acid particles $\gamma^{\mathrm{OH}}$ is likely between 0.8 and 1 . This value is in general agreement with other studies using single component organic aerosols, organic films, and SAMs (Bertram et al., 2001; Molina et al., 2004; Lambe et al., 2007; George et al., 2007). Using the same apparatus, we measure a smaller reaction probability for thin palmitic acid films $\left(\gamma^{\mathrm{OH}} \sim 0.3\right)$. Given the challenges of this particular experiment and the uncertainty in the $\mathrm{OH}$ exposure, we refrain from inferring too much from this difference; for example, if the uncorrected $\gamma^{\mathrm{OH}}$ was 0.5 , instead of 0.3 , the diffusion correction would lead to a $\gamma^{\mathrm{OH}}=1$.

For the best agreement between our model and the pure palmitic acid data, a non-zero rate constant is required for the reaction of surface-bound palmitic acid with reaction products. Our model could be improved by speciating the oxidation products into $\mathrm{RO}_{2}$ and $\mathrm{RO}$ radicals, but the scatter in the present data set doesn't provide a strong test of more complicated pathways. The main point is that our data support the existence of secondary condensed-phase chemistry, and our model suggests a fairly simple mechanism that could explain observations of reaction probabilities exceeding unity (Hearn et al., 2007). In our model, the rate of secondary reactions between $\mathrm{OH}$ oxidation products and $\mathrm{PA}$ at the surface is at a maximum when $\theta_{\mathrm{PA}} \ll 1$ and a psuedo-first order rate constant then approaches the value of $k_{2}=0.22 \mathrm{~s}^{-1}$. This rate constant can be compared to the diffusion-limited rate constant for $\mathrm{OH}$ oxidation of $\mathrm{PA}$ at the surface, a typical value being $\sim 0.45 \mathrm{~s}^{-1}$ for $[\mathrm{OH}] \sim 3 \times 10^{10} \mathrm{molec}^{-3}$ and $\mathrm{r}_{p}=150 \mathrm{~nm}$. Thus, while reaction with $\mathrm{OH}$ is the dominant fate of surface PA, secondary chemistry can account for as much as $10-30 \%$ of surface PA loss depending on the exact $\mathrm{OH}$ collision frequency in our reactor.

Formation and photolysis of organic hydroperoxides $(\mathrm{ROOH})$ is one possible mechanism that could explain our inference of secondary particle-phase chemistry which enhances palmitic acid loss. ROOH would form from the reaction of surface-bound $\mathrm{RO}_{2}$ with $\mathrm{HO}_{2}$. Subsequent loss of $\mathrm{ROOH}$ by photolysis at $254 \mathrm{~nm}$ would lead to the formation of $\mathrm{RO}$ and $\mathrm{OH}$ radicals in the condensed phase, adding to the pool of radicals formed by other pathways. The net effect of this chemistry would be to enhance the oxidation rate of palmitic acid and the branching to alkoxy radicals. The latter would enhance the degree of volatilization per collision of gaseous $\mathrm{OH}$ with the particle surface. We note that this chemistry is would possibly be important only in our experimental setup, and that of George et al. (2007), but not in 
the atmosphere. It is important to note that neither we, nor George et al. detected $\mathrm{ROOH}$ products in the particle phase.

Our evaluation of this chemistry demonstrates that it may well be occurring, but that it doesn't impact our main conclusions: namely, $\gamma^{\mathrm{OH}}>0.8$ on pure palmitic acid particles, and mass loss by volatilization due to heterogeneous $\mathrm{OH}$ oxidation is unlikely to be important in the atmosphere (see below). To evaluate the potential importance of this pathway, we incorporated $\mathrm{RO}_{2}$ and $\mathrm{ROOH}$ formation and loss into our surface-chemistry model. Due to the lack of available information about necessary parameters, we attempt to provide an upper-limit estimate by assuming that every $\mathrm{HO}_{2}$ collision with an $\mathrm{RO}_{2}$ at the surface produces an $\mathrm{ROOH}$, and that the photolysis of each ROOH leads to the oxidation of a palmitic acid molecule. We assume the photolysis frequency of $\mathrm{ROOH}$ is the same as for $\mathrm{CH}_{3} \mathrm{OOH}$, which we calculate relative to our calibrated ozone photolysis frequency using the ratio of $\mathrm{CH}_{3} \mathrm{OOH}$ and $\mathrm{O}_{3}$ absorption cross sections at $254 \mathrm{~nm}$ (De More et al., 1997). We also ran a simulation with the ROOH photolysis frequency a factor of 100 larger than this value. We do not allow for any other secondary loss processes of palmitic acid. Under these circumstances, the model generally reproduces the observed palmitic acid decay, especially at the higher $\mathrm{OH}$ exposures, but continues to underestimate palmitic acid loss at low $\mathrm{OH}$ exposures. We require $\gamma^{\mathrm{OH}} \sim 1-1.4$ to simulate the palmitic acid loss, with the values above unity suggesting that not all loss processes have been identified. Thus, ROOH chemistry, as we have modeled here, can explain a significant fraction of the inferred secondary chemistry required in the simpler model, but this chemistry does not affect the large $\gamma^{\mathrm{OH}}$ inferred for this system.

A surface renewal process is needed to explain our observation that more PA is oxidized than is initially present in the surface layer. If we assume this renewal process is driven by volatilization, then our parameterization suggests that essentially two oxidation events of a PA molecule leads to volatilzation and the exposure of a new palmtic acid at the surface. This conclusion is based on the value of $\mathrm{k}_{\mathrm{ren}}$ being similar to the typical psuedo-first order rate coefficient for $\mathrm{OH}$ striking a surface-bound $\mathrm{PA}\left(\sim 0.45 \mathrm{~s}^{-1}\right)$ and that the renewal rate scales with the coverage of oxidation products. Molina et al. (2004) found using SAMs that roughly 6-9 carbons were volatilized per $\mathrm{OH}$ collision. For palmitic acid, if one $\mathrm{OH}$ reaction event were to volatilize 6 carbons, the first event would lead to an oxidized $\mathrm{C}_{10}$ product that may be of low enough volatility to remain in the particle phase. Reaction of this $\mathrm{C}_{10}$ product would lead to a $\mathrm{C}_{4}$ and a $\mathrm{C}_{6}$ product, both potentially volatile. Thus, our results seem roughly consistent with this level of volatilization by $\mathrm{OH}$ oxidation of PA. We expand on this issue below. An alternative to volatilization as the renewal process is liquification of the surface layer upon oxidation, which would be thermodynamically expected (Marcolli et al., 2004). This liquification would provide a means for bulk PA to migrate rapidly to the surface and/or for $\mathrm{OH}$ to diffuse more rapidly into the subsurface region. The fact that we observe low molecular weight products and a decrease in electrical mobility diameter supports volatilization as a viable surface renewal process.

To best reproduce the observed decrease in electrical mobility diameter, the radius must change essentially at the same rate as PA, i.e. $\chi_{\text {vap }} \sim 0.9$. Given that the bulk palmitic acid loss rate in the model is largely controlled by the surface renewal process, the observed decrease in size also suggests volatilization. An implication of the radius change being tied to the PA oxidation rate is that the rate of volatilization is not constant with $\mathrm{OH}$ exposure, i.e. aging. Indeed, our results suggest that the particle size should eventually stop changing with very high $\mathrm{OH}$ exposures. We infer that the oxidized material that remains in the particle phase becomes less likely to volatilize upon collision with $\mathrm{OH}$. If volatilization is tied only to the oxidation of a PA molecule, and the surface renewal process is via liquification, then experiments to supress the surface renewal rate, for example, cooling the particle stream, should yield smaller decreases in particle size for the same $\mathrm{OH}$ exposures used here.

Electrical mobility diameter depends on other factors such as particle shape, which is also likely changing if the pure palmitic particles initially have a rough crystalline morphology that becomes smoothed by oxidation or liquification. Taking all the results together, however, we feel it reasonable to conclude that particle mass loss by volatilization initially occurs with an effeciency similar to that observed by Molina, et al. (2004) leading to an overall decrease in the size of pure palmitic acid particles upon $\mathrm{OH}$ exposure, but that the efficiency of volatilization per $\mathrm{OH}$ collision decreases exponentially with $\mathrm{OH}$ exposure such that this process would likely become unimportant in the atmosphere as an organic aerosol mass loss. In addition, $\mathrm{ROOH}$ production and subsequent photolysis would enhance the flux through alkoxy radicals, and thus enhance the potential for volatilazation by RO decomposition. Above, we estimate that ROOH chemistry may be occuring in our system to an extent that is greater than would occur in the atmosphere, and thus some fraction of the observed volatilization could be due to these unrealistic conditions which would further limit the actual importance of volatilization as an organic aerosol mass loss.

\section{Summary and atmospheric implications}

The loss rate of PA in the particle phase, as observed for pure PA aerosols and PA-coated solid $\mathrm{NaCl}$ aerosols, indicates that the $\mathrm{OH}$ oxidation of $\mathrm{PA}$ at the gas-aerosol interface is efficient, with $\gamma^{\mathrm{OH}}$ ranging from 0.3 for thin palmitic acid films on solid substrates to $\sim 1$ for pure palmitic acid particles. Interestingly, for thin palmitic acid films on aqueous substrates we infer a substantially lower $\gamma^{\mathrm{OH}}$ of $\sim 0.05 \mathrm{im}-$ plying that mophology of the organic surface may impact the $\mathrm{OH}$ oxidation rate. 
For all aerosol types studied, many of the observed oxidation products were volatile at $298 \mathrm{~K}$. We observed a reduction in volume-weighted mean particle diameter of up to $12 \%$ for $90 \mathrm{~nm}$ palmitic acid particles, which corresponds to a maximum volume loss of $\sim 30 \%$ after an equivalent 6 days of $\mathrm{OH}$ processing in the atmosphere. The kinetics and particle size change data for $\mathrm{OH}$ oxidation of pure PA aerosols are well-represented by a model consisting of surface-only reactions with volatilization of products, surface renewal, and secondary chemistry between PA and oxidation products. These results suggest that alkoxy radical formation followed by bond scission to produce low-molecular weight products is active in this system with an efficiency similar to the lower end of that observed by Molina, et al. (2004). This pathway can be a potentially important source of OVOCs in the upper troposphere, as well as a potentially important sink for organic aerosol mass. The initial mass loss rates observed in this study, which utilized highly aliphatic particles, are consistent with estimates by Kwan et al. (2006) that organic aerosol oxidation may result in OVOC fluxes of up to 70 pptv C/day. However, the importance of this pathway appears to depend on oxidant type, particle type (Knopf et al., 2006; George et al., 2007; Hearn et al., 2007; Vlasenko et al., 2008), and particle age as implied by our results. As such, it is unlikely that a persistent $70 \mathrm{pptv} \mathrm{C} /$ day OVOC source exists in the upper troposphere and unlikely that mass loss by volatilization will compete significantly as a control on overall particle lifetime.

In comparing our data to studies utilizing liquid particles, we observe, consistent with our expectations, that the heterogeneous oxidation rate of organic aerosol mass is fastest for material residing at the surface, rather than the bulk. This gradient in oxidation rates is steeper for particles that are solid, such as palmitic acid particles used here, compared to those that are liquids. Atmospheric aerosol particles are certainly complex mixtures of multiple components, and it is possible some particles are more solid, structured or otherwise diffusion-resistant than others. Likewise, liquid particles may undergo phase transitions in the colder upper troposphere which could affect their chemistry (Hearn and Smith, 2005, 2007). These issues may preclude the use of a single constant reaction probability in models, and the sensitivity of predicted organic aerosol loadings and OVOC concentrations to these effects should be assessed.

Finally, we show that hypothetical experiments which vary interaction time while keeping $[\mathrm{OH}]$ constant may exhibit different oxidation kinetics from those which vary $[\mathrm{OH}]$ while keeping the interaction time constant. The differences in the model output for the two experiment types are due to surface renewal and secondary chemistry processes, with implications for experiment designs or comparisons between different data sets along the $\mathrm{OH}$ exposure coordinate.
Acknowledgements. This work was funded in large part by a grant from the Office of Earth Science (NIP/03-0000-0025) at the National Aeronautics and Space Administration (NASA). R. L. N. Y. was supported in part by a NASA Earth and Space Science Fellowship. V. F. M and R. L. N. Y. contributed equally to the acquisition of the data and modelling presented in this manuscript.

Edited by: T. Hoffmann

\section{References}

Adam, N. K.: The properties and molecular structure of thin films of palmitic acid on water. Part I, Proc. Roy. Soc. London A, 99, 336-351, 1921.

Ammann, M., Poschl, U., and Rudich, Y.: Effects of reversible adsorption and Langmuir-Hinshelwood surface reactions on gas uptake by atmospheric particles, Phys. Chem. Chem. Phys., 5, 351-356, 2003.

Atkinson, R.: Kinetics and mechanisms of the gas-phase reactions of the hydroxyl radical with organic compounds under atmospheric conditions, Chem. Rev., 86, 69-201, 1986.

Bertram, A. K., Ivanov, A. V., Hunter, M., Molina, L. T., and Molina, M. J.: The reaction probability of $\mathrm{OH}$ on organic surfaces of tropospheric interest, J. Phys. Chem. A, 105, 9415-9421, 2001.

Cziczo, D. J., Nowak, J. B., Hu, J. H., and Abbatt, J. P. D.: Infrared spectroscopy of model tropospheric aerosols as a function of relative humidity: Observation of deliquescence and crystallization, J. Geophys. Res.-Atmos., 102, 18 843-18 850, 1997.

DeMore, W. B., Sander, S. P., Golden, D. M., Hampson, R. F., Kurylo, M. J., Howard, C. J., Ravishankara, A. R., Kolb, C. E., and Molina, M. J.: Chemical kinetics and photochemical data for use in stratospheric modeling, National Aeronautics and Space Administration Jet Propulsion Laboratory, Pasadena, CA, USA, 1997.

Eliason, T. L., Gilman, J. B., and Vaida, V.: Oxidation of organic films relevant to atmospheric aerosols, Atmos. Environ., 38, 1367-1378, 2004.

Ellison, G. B., Tuck, A. F., and Vaida, V.: Atmospheric processing of organic aerosols, J. Geophys. Res.-Atmos., 104, 11633 $11641,1999$.

Forster, P., Ramaswamy, V., Artaxo, P., Berntsen, T., Betts, R., Fahey, D. W., Haywood, J., Lean, J., Lowe, D. C., Myhre, G., Nganga, J., Prinn, R., Raga, G., Schulz, M., and Van Dorland, R.: Changes in atmospheric constituents and in Radiative Forcing, in: Climate Change 2007: The Physical Science Basis. Contribution of Working Group I to the Fourth Assessment Report of the Intergovernmental Panel on Climate Change, edited by: Solomon, S., Qin, D., Manning, M., Chen, Z., Marquis, M., Averyt, K. B., Tignor, M., and Miller, H. L., Cambridge University Press, Cambridge, UK and New York, NY, USA, 2007.

Fuchs, N. A. and Sutugin, A. G.: Highly Dispersed Aerosols, Ann Arbor Science Pulishers, Ann Arbor, 47-59, 1970.

George, I. J., Vlasenko, A., Slowik, J. G., Broekhuizen, K., and Abbatt, J. P. D.: Heterogeneous oxidation of saturated organic aerosols by hydroxyl radicals: Uptake kinetics, condensed-phase products, and particle size change, Atmos. Chem. Phys., 7, 4187-4201, 2007,

http://www.atmos-chem-phys.net/7/4187/2007/. 
Gill, P. S., Graedel, T. E., and Weschler, C. J.: Organic films on atmospheric aerosol-particles, fog droplets, cloud droplets, raindrops, and snowflakes, Rev. Geophys., 21, 903-920, 1983.

Hanson, D. R., Ravishankara, A. R., and Solomon, S.: Heterogeneous reactions in sulfuric-acid aerosols - A framework for model calculations, J. Geophys. Res.-Atmos., 99, 3615-3629, 1994.

Hearn, J. D., Renbaum, L. H., Wang, X., and Smith, G. D.: Kinetics and products from a reaction of $\mathrm{Cl}$ radicals with dioctyl sebacate (DOS) particles in $\mathrm{O}_{2}$ : a model for radical-initiated oxidation of organic aerosols, Phys. Chem. Chem. Phys., 9, 1-11, 2007.

Hearn, J. D. and Smith, G. D.: A chemical ionization mass spectrometry method for the online analysis of organic aerosols, Anal. Chem., 76, 2820-2826, 2004.

Hearn, J. D. and Smith, G. D.: Measuring rates of reaction in supercooled organic particles with implications for atmospheric aerosol, Phys. Chem. Chem. Phys., 7, 2549-2551, 2005.

Hearn, J. D. and Smith, G. D.: Ozonolysis of mixed oleic $\mathrm{acid} / n$-docosane particles: The roles of phase, morphology, and metastable states, J. Phys. Chem. A, 111, 11 059-11 065, 2007.

Jacob, D. J.: Heterogeneous chemistry and tropospheric ozone, Atmos. Environ., 34, 2131-2159, 2000.

Kanakidou, M., Seinfeld, J. H., Pandis, S. N., Barnes, I., Dentener, F. J., Facchini, M. C., Van Dingenen, R., Ervens, B., Nenes, A., Nielsen, C. J., Swietlicki, E., Putaud, J. P., Balkanski, Y., Fuzzi, S., Horth, J., Moortgat, G. K., Winterhalter, R., Myhre, C. E. L., Tsigaridis, K., Vignati, E., Stephanou, E. G., and Wilson, J.: Organic aerosol and global climate modelling: A review, Atmos. Chem. Phys., 5, 1053-1123, 2005,

http://www.atmos-chem-phys.net/5/1053/2005/.

Katrib, Y., Biskos, G., Buseck, P. R., Davidovits, P., Jayne, J. T., Mochida, M., Wise, M. E., Worsnop, D. R., and Martin, S. T.: Ozonolysis of mixed oleic-acid/stearic-acid particles: Reaction kinetics and chemical morphology, J. Phys. Chem. A, 109, 10910-10919, 2005.

Knopf, D. A., Anthony, L. M., and Bertram, A. K.: Reactive uptake of $\mathrm{O}_{3}$ by multicomponent and multiphase mixtures containing oleic acid, J. Phys. Chem. A, 109, 5579-5589, 2005.

Knopf, D. A., Mak, J., Gross, S., and Bertram, A. K.: Does atmospheric processing of saturated hydrocarbon surfaces by $\mathrm{NO}_{3}$ lead to volatilization?, Geophys. Res. Lett., 33, L17816, doi:10.1029/2006GL026884, 2006.

Kwamena, N. O. A., Thornton, J. A., and Abbatt, J. P. D.: Kinetics of surface-bound benzo[a]pyrene and ozone on solid organic and salt aerosols, J. Phys. Chem. A, 108, 11 626-11 634, 2004.

Kwan, A. J., Crounse, J. D., Clarke, A. D., Shinozuka, Y., Anderson, B. E., Crawford, J. H., Avery, M. A., McNaughton, C. S., Brune, W. H., Singh, H. B., and Wennberg, P. O.: On the flux of oxygenated volatile organic compounds from organic aerosol oxidation, Geophys. Res. Lett., 33, L15815, doi:10.1029/2006GL026144, 2006.
Lambe, A. T., Zhang, J. Y., Sage, A. M., and Donahue, N. M.: Controlled $\mathrm{OH}$ radical production via ozone-alkene reactions for use in aerosol aging studies, Environ. Sci. Technol., 41, 23572363, 2007.

Liao, H. and Seinfeld, J. H.: Global impacts of gas-phase chemistry-aerosol interactions on direct radiative forcing by anthropogenic aerosols and ozone, J. Geophys. Res.-Atmos., 110, doi:10.1029/2005JD005907, 2005.

Marcolli, C., Luo, B. P., and Peter, T.: Mixing of the organic aerosol fractions: Liquids as the thermodynamically stable phases, J. Phys. Chem. A, 108, 2216-2224, 2004.

Maria, S. F., Russell, L. M., Gilles, M. K., and Myneni, S. C. B.: Organic aerosol growth mechanisms and their climate-forcing implications, Science, 306, 1921-1924, 2004.

McNell, V. F., Wolfe, G. M., and Thornton, J. A.: The oxidation of oleate in submicron aqueous salt aerosols: Evidence of a surface process, J. Phys. Chem. A., 111, 1073-1083, 2007.

McNeill, V. F., Patterson, J., Wolfe, G. M., and Thornton, J. A.: The effect of varying levels of surfactant on the reactive uptake of $\mathrm{N}_{2} \mathrm{O}_{5}$ to aqueous aerosol, Atmos. Chem. Phys., 6, 1635-1644, 2006, http://www.atmos-chem-phys.net/6/1635/2006/.

Molina, M. J., Ivanov, A. V., Trakhtenberg, S., and Molina, L. T.: Atmospheric evolution of organic aerosol, Geophys. Res. Lett., 31, L22104, doi:10.1029/2004GL020910, 2004.

Myers, D.: Surfactant science and technology, John Wiley and Sons, Hoboken, NJ, USA, 107-157, 2006.

Rudich, Y., Donahue, N. M., and Mentel, T. F.: Aging of organic aerosol: Bridging the gap between laboratory and field studies, Annu. Rev. Phys. Chem., 58, 321-352, 2007.

Tang, I. N., Tridico, A. C., and Fung, K. H.: Thermodynamic and optical properties of sea salt aerosols, J. Geophys. Res.-Atmos., 102, 23 269-23 275, 1997.

Thornton, J. A., Braban, C. F., and Abbatt, J. P. D.: $\mathrm{N}_{2} \mathrm{O}_{5}$ hydrolysis on sub-micron organic aerosols: the effect of relative humidity, particle phase, and particle size, Phys. Chem. Chem. Phys., 5, 4593-4603, 2003.

Worsnop, D. R., Morris, J. W., Shi, Q., Davidovits, P., and Kolb, C. E.: A chemical kinetic model for reactive transformations of aerosol particles, Geophys. Res. Lett., 20, p. 1996, doi:10.1029/2002GL015542, 2002.

Vlasenko, A. George, I. J., and Abbatt, J. P. D.: Formation of volatile organic compounds in the heterogeneous oxidation of condensed-phase organic films by gas-phase OH, J. Phys. Chem. A, ASAP Article, 112, doi:10.1021/jp0772979, 15521560, 2008. 